\title{
Detección y susceptibilidad antimicrobiana de Shigella spp. en ensaladas preparadas, listas para consumir
}

\author{
Ricardo J. Anselmo*, Pablo A. Ojeda y Hebe A. Barrios \\ Universidad Nacional de Luján, Depto. de Cs. Básicas, Casilla 221, Luján-Buenos Aires-Argentina \\ (e-mail: anselmoricardoj@gmail.com)
}

* Autor a quien debe ser dirigida la correspondencia.

Recibido May. 7, 2019; Aceptado Jun. 29, 2019; Versión final Ago. 1, 2019, Publicado Feb. 2020

\begin{abstract}
Resumen
El objetivo de este estudio fue investigar la presencia de Shigella spp. en ensaladas de vegetales y verificar la resistencia antibiótica de los aislamientos obtenidos. Ciento sesenta muestras de ensaladas preparadas, listas para consumir fueron obtenidas de cinco lugares de expendio de la ciudad de Luján, provincia de Buenos Aires, Argentina, durante los meses de enero 2017 a diciembre 2018. Se determinó la presencia de Shigella spp. y su resistencia antibiótica por métodos microbiológicos estándares. Shigella fue aislada de 13 muestras $(8,12 \%)$ por análisis bioquímico y tipificación serológica. De los 13 aislamientos, cuatro de Shigella flexneri serotipo 2 manifestaron una multi-resistencia a ampicilina, cloranfenicol y trimetoprim-sulfametoxazol, mientras que el resto manifestó resistencia a un solo antibiótico. Puede concluirse que las ensaladas preparadas, listas para consumir, constituyen un alto riesgo de contraer shigelosis debido a que son consumidas sin tratamiento previo.
\end{abstract}

Palabras clave: Shigella spp.; ensaladas preparadas; resistencia antibiótica; shigelosis

\section{Detection and antimicrobial susceptibility of Shigella spp. in prepared, ready to eat salads}

\begin{abstract}
The objective of this study was to investigate the presence of Shigella spp. in vegetable salads and verify the antibiotic resistance of the obtained samples. One hundred and sixty samples of ready-to-eat salads were obtained from five places of sale in the city of Lujan, province of Buenos Aires, Argentina, during the months of January 2017 to December 2018. The presence of Shigella spp. and their antibiotic resistance was determined following standard microbiological methods. Shigella was isolated from 13 samples $(8.12 \%)$ by biochemical analysis and serological typing. Of the 13 isolates, four of Shigella flexneri serotype 2 showed a multidrug resistance to ampicillin, chloramphenicol and trimethoprim-sulfamethoxazole, while the rest showed resistance to a single antibiotic. It can be concluded that prepared salads, ready to consume, possess a high risk of contracting shigellosis because they are consumed without prior treatment.
\end{abstract}

Keywords: Shigella spp; prepared salads; antibiotic resistance; shigellosis 


\section{INTRODUCCIÓN}

Durante las últimas décadas, diferentes investigaciones científicas han demostrado que una dieta rica en frutas y hortalizas ofrece una protección contra muchas enfermedades. Esto, junto con el poco tiempo con que cuenta gran parte de la población para cocinar en días laborales sus alimentos, ha incrementado el consumo de ensaladas preparadas, listas para consumir, procedentes de diferentes lugares de expendio. Sin embargo, un número de alimentos crudos o no cocidos ha sido vinculados a brotes de shigelosis incluyendo lechuga, perejil, ensalada de legumbres, bocadillos fritos, ensalada de papas, ensalada de tofú, ensalada de huevos, hamburguesas, tomates y ostras (Brandl, 2006; Deza et al., 2003; Haley et al., 2010; Nutt, 2003). El género está dividido en cuatro serogrupos: A o Shigella dysenteriae, incluye 15 serotipos; B o Shigella flexneri, incluye 8 serotipos, C o Shigella boydii con 20 serotipos; y D o Shigella sonnei, que contiene un único serotipo, que se puede presentar de dos formas, la forma I (lisa) y la forma II (rugosa). Son bacilos Gramnegativos, no esporulados, facultativamente anaeróbicos, inmóviles de la familia Enterobacteriaceae. No decarboxilan lisina ni fermentan lactosa dentro de las 48 horas. Utilizan glucosa y otros carbohidratos, produciendo ácido pero no gas. Aunque, debido a su afinidad con Escherichia coli, excepciones frecuentes pueden hallarse, por ejemplo, algunos biotipos producen gas de glucosa y manitol. Ninguno utiliza citrato ni malonato como únicas fuentes de carbono para crecer, y son inhibidos por el cianuro de potasio (Della Gaspera et al., 2015).

La transmisión de Shigella spp. puede ocurrir indistintamente por consumo de alimentos crudos o procesados de cualquier origen. Por lo general, las prácticas de higiene personal deficientes por parte del manipulador de alimentos en la etapa final de preparación o servicio de alimentos se consideran como el principal factor de contaminación de los alimentos. El manipuleo de múltiples ingredientes que sufren las ensaladas probablemente convierten a este alimento listo para consumir como vehículo predominante de shigelosis de origen alimentario (Food Microbiology, 2013; Petri et al., 2008). Además, una vez excretadas las células de Shigella son muy sensibles a las condiciones ambientales y mueren rápidamente, particularmente cuando se exponen a la luz solar directa o la deshidratación. Por este motivo, lograr el aislamiento de Shigella a partir de alimentos todavía es un desafío. Muchas características adicionales del alimento como su composición, parámetros físicos ( $\mathrm{pH}$ y concentración salina), y la flora microbiana natural que compite por los nutrientes, pueden afectar el aislamiento exitoso de shigelas (Bad Bug Book, 2012). Además, se requieren métodos de enriquecimiento especiales para una detección exitosa de Shigella en alimentos, ya que esta bacteria puede hallarse presente en bajo número o en un estado fisiológico debilitado (WHO, 2005).

En la actualidad, existen numerosos puntos de venta locales que distribuyen productos frescos en la ciudad de Luján, Buenos Aires, Argentina. Los principales proveedores de vegetales los constituyen las quintas de diferentes partes de la localidad que utilizan agua generalmente insalubre para la irrigación. A su vez varios microorganismos indeseables pueden hallarse presentes en las verdulerías que los expenden. Esto se vuelve particularmente importante en las ensaladas de vegetales que son preparadas y consumidas sin ningún tratamiento térmico. En este contexto, el objetivo del presente estudio fue determinar la presencia de Shigella spp. en ensaladas preparadas, listas para consumir y su perfil de resistencia a antibióticos.

\section{METODOLOGIA}

Durante el período enero 2017 a diciembre 2018 se tomaron 160 muestras de ensaladas preparadas, listas para consumir, de cinco lugares de expendio de la ciudad de Luján, Buenos Aires, Argentina. Cuarenta muestras consistieron en brotes de soja, 40 de zanahoria rallada, 40 de repollo cortado y las 40 restantes de ensalada mixta constituida por lechuga cortada en tiritas, cebolla cortada y tomates Cherry. La totalidad de las muestras analizadas se encontraban en bandejas plásticas descartables cubiertas con un film plástico termosellable y se tuvo la precaución que arriben al laboratorio en sus envases inalterados. Después de la toma, las muestras se colocaron en un contenedor isotérmico con gel refrigerante con la finalidad de que no se altere la microflora existente y características de la muestra, luego se transportaron al Laboratorio de Microbiología de la Universidad Nacional de Luján, Buenos Aires, Argentina. Todas las muestras fueron procesadas dentro de las 2 horas de la toma de muestra durante los meses de enero de 2017 a diciembre de 2018.

\section{Aislamiento de Shigella spp.}

Se preparó una dilución $10^{-1}$, pesando $25 \mathrm{~g}$ de muestra de forma aséptica en una bolsa estéril para homogeneizadores Tipo Stomacher de $400 \mathrm{~mL}$ de capacidad con pinza estéril. En el caso particular de la ensalada mixta los $25 \mathrm{~g}$ se hallaban integrados por cantidades equivalentes de cada componente es decir lechuga cortada en tiritas, cebolla cortada y tomates Cherry. Luego se adicionaron $225 \mathrm{~mL}$ de Agua de Peptona Tamponada (Oxoid) al $2 \%$ a la bolsa plástica con los $25 \mathrm{~g}$ de muestra y se trasfirió al homogeneizador de palas Tipo Stomacher, en el cual se agitó durante 2 minutos a $260 \mathrm{rpm}$. De inmediato se realizó un 
aislamiento inoculando en estría en placas de agar MacConkey (Oxoid), agar xilosa-lisina-desoxicolato (Oxoid) y agar entérico de Hektoen (Oxoid). A continuación las bolsas conteniendo la dilución $10^{-1}$ de la muestra se incubaron a $35 \pm 0,5^{\circ} \mathrm{C}$ por $24 \pm 2 \mathrm{~h}$ para revitalización y se repitió el aislamiento inoculando en estría en idénticos agares selectivos y diferenciales (Goud et al., 2018). Todas las placas se incubaron a 35 $\pm 0,5^{\circ} \mathrm{C}$ por $24 \pm 2 \mathrm{~h}$ en busca de colonias características de Shigella spp. y las que no presentaban colonias presuntivas se reincubaron un adicional de $24 \pm 2 \mathrm{~h}$. Cinco colonias características de cada placa se reaislaron en agar MacConkey (Oxoid) y se repicaron a agar nutritivo (Oxoid) inclinado. Luego de incubar los tubos a 35 $\pm 0.5^{\circ} \mathrm{C}$ por 18 a $24 \mathrm{~h}$ se continuó según la metodología estándar para Shigella en aguas (Manual of Methods of Analysis of Foods: Water, 2016) para su identificación bioquímica y tipificación serológica.

\section{Susceptibilidad de los aislamientos}

La prueba de susceptibilidad antimicrobiana de los aislamientos se realizó en agar Mueller-Hinton y los antibióticos probados incluyen ampicilina $(10 \mu \mathrm{g})$, cefotaxima $(30 \mu \mathrm{g})$, ciprofloxacina $(05 \mu \mathrm{g})$, trimetoprimsulfametoxazol $(25 \mu \mathrm{g})$, cloranfenicol $(30 \mu \mathrm{g})$ y furazolidona $(50 \mu \mathrm{g})$ (Barrantes et al., 2013; Biniam y Mogessie, 2010). Las lecturas del disco se realizaron 24 horas después de la incubación y el diámetro de los halos de inhibición se midió con la ayuda de una regla. Los resultados se obtuvieron según la tabla de interpretación de tamaño de zona proporcionada por el fabricante de los discos.

\section{RESULTADOS}

En la figura 1 se muestra que del total de las muestras analizadas, Shigella fue aislada a partir de $13(8,12 \%)$ (un aislamiento por muestra) solamente cuando se sometió a un enriquecimiento previo en Agua de Peptona Tamponada. Seis muestras de brotes de soja $(3,75 \%)$, tres muestras de zanahoria rallada $(1,87 \%)$, dos muestras de repollo cortado $(1,25 \%)$ y dos muestras de ensalada mixta $(1,25 \%)$ resultaron positivos para Shigella spp. por análisis bioquímico y tipificación serológica.

En cambio cuando se realizaron los aislamientos directos en placas de agar selectivos y diferenciales a partir de la dilución $10^{-1}$ de la muestra, sin someterse a incubación para revitalización, a pesar de haber desarrollado colonias con características similares a Shigella spp., ninguna correspondió a esta bacteria patógena. Cabe mencionar que alrededor del $50 \%$ de estos aislamientos se ha podido descartar al ser identificados mediante las pruebas bioquímicas exclusivamente. Mientras que el $50 \%$ remanente si bien pasó la identificación bioquímica, recién en la tipificación serológica se determinó que se trataba de una bacteria fitopatógena, que se encuentra con mucha frecuencia en los vegetales frescos conocida como Pantoea stewartii.

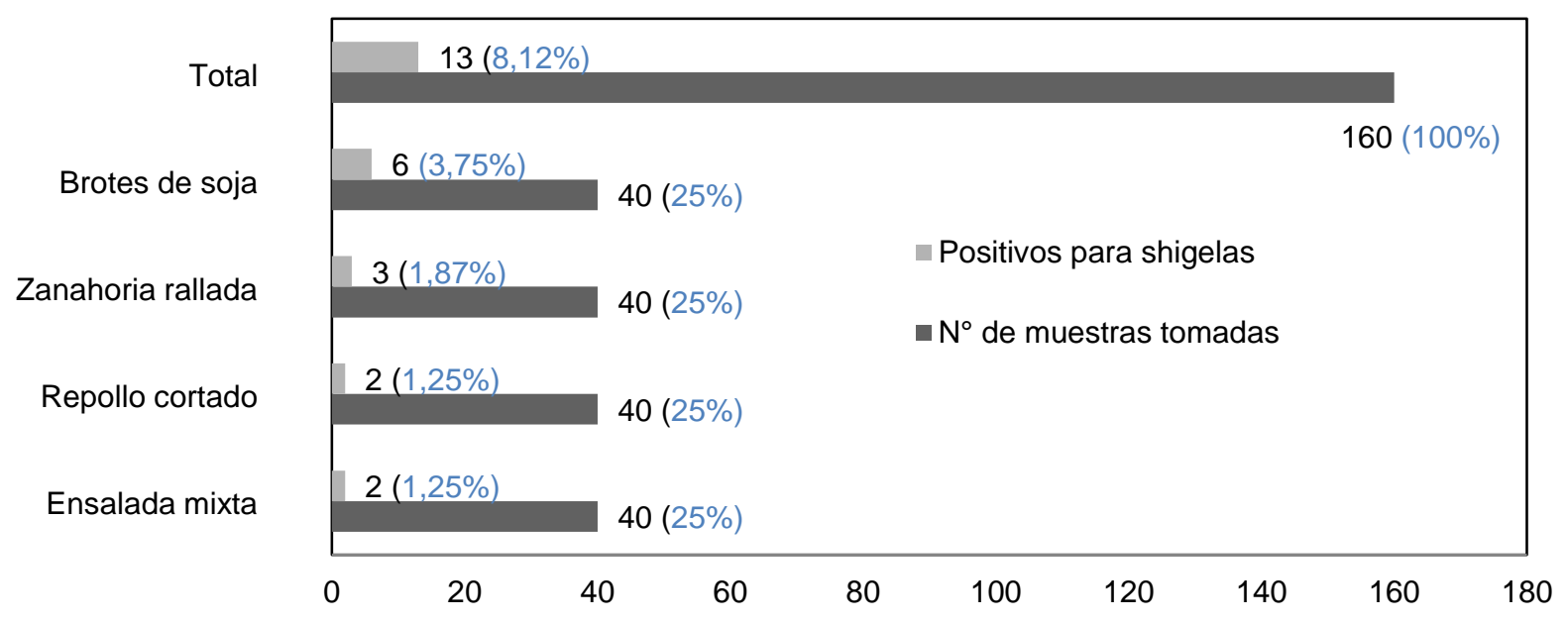

Fig. 1. Presencia de Shigella spp. en muestras de ensaladas

Los resultados de las pruebas bioquímicas para la confirmación del género de Enterobacteriaceae se muestran en la tabla 1. Tanto en agar hierro tres azúcares como en agar hierro lisina, los aislamientos produjeron una reacción neutra en la pendiente y una columna ácida sin la producción de ácido sulfhídrico ni producción de gas. De todas las pruebas bioquímicas, resultados negativos fueron registrados en oxidasa, gas de glucosa, movilidad, ureasa, L-lisina y L-ornitina decarbosilasas, Voges-Proskauer, utilización de citrato y acetato de sodio, fermentaciones de lactosa, sacarosa y adonitol. En cambio los resultados de fermentación de manitol, dulcitol, sorbitol, arabinosa, rafinosa y melobiosa fueron variables. De los 13 aislamientos obtenidos, se determinó mediante su tipificación serológica que siete $(53,85 \%)$ fueron Shigella flexneri serotipo 2, cuatro (30,77\%) Shigella flexneri serotipo 1 y dos (15,38\%) Shigella boydii serotipo 2. 
Tabla 1. Porcentaje de positividad en las pruebas bioquímicas para la identificación del género Shigella

\begin{tabular}{|c|c|}
\hline Pruebas & Shigella \\
\hline Reacción de Gram & $\begin{array}{c}\text { Bacilos Gram negativos, } \\
\text { no esporulados }\end{array}$ \\
\hline Catalasa & 100 \\
\hline Oxidasa & 0 \\
\hline Medio O/F de Hugh y Leifson & Fermentativo \\
\hline $\mathrm{H}_{2} \mathrm{~S}$ en Agar hierro tres azúcares & 0 \\
\hline Gas de glucosa & 0 \\
\hline Movilidad & 0 \\
\hline Ureasa & 0 \\
\hline L-lisina decarboxylasa & 0 \\
\hline L-ornitina decarboxilasa & 0 \\
\hline Voges-Proskauer & 0 \\
\hline Utilización de citrato de sodio & 0 \\
\hline Utilización de acetato de sodio & 0 \\
\hline Acido de glucosa & 100 \\
\hline Lactosa & 0 \\
\hline Sucrosa & 0 \\
\hline Manitol & 93 \\
\hline Dulcitol & 0 \\
\hline Adonitol & 0 \\
\hline Sorbitol & 30 \\
\hline Arabinosa & 60 \\
\hline Rafinosa & 50 \\
\hline Melobiosa & 48 \\
\hline
\end{tabular}

El perfil de susceptibilidad antimicrobiana de los 13 aislamientos reveló que seis $(46,15 \%)$ manifestaron resistencia a ampicilina, cinco (38,46\%) resistentes a ciprofloxacina, cuatro (30,77\%) a trimetoprimsulfametoxazol y cloranfenicol respectivamente y; una $(7,70 \%)$ a cefotaxina y furazolidona también respectivamente como se muestra en la tabla 2 . Cabe destacar que cuatro $(57,14 \%)$ de los aislamientos de Shigella flexneri serotipo 2 manifestaron una multirresistencia a ampicilina, trimetoprim-sulfametoxazol y cloranfenicol. Mientras que de los nueve (42,86\%) aislamientos remanentes, siete $(77,78 \%)$ de Shigella flexneri serotipos 1 y 2 y; dos (22,22\%) de Shigella boydii serotipo 2 mostraron resistencia a un solo antibiótico como se muestra en la tabla 3.

Tabla 2: Perfiles de sensibilidad antimicrobiana / Intermedia / Resistencia de los aislamientos de Shigella de las diferentes ensaladas

\begin{tabular}{|c|l|c|c|c|c|}
\hline Antibiótico $N^{\circ}$ & \multicolumn{1}{|c|}{ Antibiótico } & $\begin{array}{c}N^{\circ} \text { de } \\
\text { aislamientos }\end{array}$ & $\begin{array}{c}\text { Sensibilidad } \\
\%\end{array}$ & $\begin{array}{c}\text { Sensibilidad } \\
\text { intermedia } \%\end{array}$ & $\begin{array}{c}\text { Resistencia } \\
\%\end{array}$ \\
\hline 1 & Ampicilina & 13 & $6(46,15)$ & $1(7,70)$ & $6(46,15)$ \\
\hline 2 & Cefotaxima & 13 & $11(84,60)$ & $1(7,70)$ & $1(7,70)$ \\
\hline 3 & Ciprofloxacina & 13 & $4(30,77)$ & $4(30,77)$ & $5(38,46)$ \\
\hline 4 & Furazolidona & 13 & $11(84,60)$ & $1(7,70)$ & $1(7,70)$ \\
\hline 5 & $\begin{array}{l}\text { Trimetoprim- } \\
\text { sulfametoxazol }\end{array}$ & 13 & $9(69,23)$ & $0(0,00)$ & $4(30,77)$ \\
\hline 6 & Cloranfenicol & 13 & $4(30,77)$ & $5(38,46)$ & $4(30,77)$ \\
\hline
\end{tabular}


Tabla 3: Resistencia antimicrobiana de los serotipos de Shigella aislados

\begin{tabular}{|l|c|c|c|}
\hline \multicolumn{1}{|c|}{ Antimicrobiano } & $\begin{array}{c}\text { Shigella flexneri } 2 \\
N^{\circ}=7(\%)\end{array}$ & $\begin{array}{c}\text { Shigella flexneri 1 } \\
N^{\circ}=4(\%)\end{array}$ & $\begin{array}{c}\text { Shigella boydii 2 } \\
N^{\circ}=2(\%)\end{array}$ \\
\hline Ampicilina & $4(57,14)$ & $1(25,00)$ & $1(50,00)$ \\
\hline Cefotaxima & $1(14,29)$ & $0(0,00)$ & $0(0,00)$ \\
\hline Ciprofloxacina & $2(28,57)$ & $2(50,00)$ & $1(50,00)$ \\
\hline Furazolidona & $0(0,00)$ & $1(25,00)$ & $0(0,00)$ \\
\hline Trimetoprim-sulfametoxazol & $4(57,14)$ & $0(0,00)$ & $0(0,00)$ \\
\hline Cloranfenicol & $4(57,14)$ & $0(0,00)$ & $0(0,00)$ \\
\hline
\end{tabular}

Dentro de la flora dominante de acompañamiento, que creció en los medios de agar selectivos y diferenciales utilizados en el presente trabajo dando colonias características muy similares a Shigella spp., se encontró una variedad de grupos bacterianos Gram positivos y Gram negativos como se muestra en la tabla 4. Cabe destacar que las bacterias Gram positivas han desarrollado exclusivamente en el agar MacConkey que de acuerdo a su composición en más diferencial que selectivo mientras que fueron incapaces de desarrollar en los otros dos medios utilizados al ser mucho más selectivos que el primero.

Tabla 4: Bacterias dominantes presentes en las muestras analizadas

\begin{tabular}{|c|c|c|c|c|c|c|c|c|c|}
\hline \multirow{2}{*}{$\begin{array}{l}\text { Tipo de } \\
\text { Muestra }\end{array}$} & \multirow{2}{*}{$\begin{array}{c}N^{\circ} \\
/ \\
\text { muestra }\end{array}$} & \multicolumn{8}{|c|}{ Porcentaje } \\
\hline & & Erwinia & Pantoea & Pectobacterium & Pseudomonas & Alcaligenes & Aeromonas & Staphylococcus & $\begin{array}{c}\text { Otros } \\
\text { bacilos } \\
\text { Gram } \\
\text { positivos }\end{array}$ \\
\hline $\begin{array}{l}\text { Brotes de } \\
\text { soja }\end{array}$ & 378 & 8 & 48 & 6 & 15 & 3 & 6 & 9 & 5 \\
\hline $\begin{array}{l}\text { Zanahoria } \\
\text { rallada }\end{array}$ & 261 & 4 & 52 & 7 & 6 & 8 & 5 & 11 & 7 \\
\hline $\begin{array}{l}\text { Repollo } \\
\text { cortado }\end{array}$ & 229 & 6 & 46 & 2 & 5 & 4 & 12 & 7 & 18 \\
\hline $\begin{array}{l}\text { Ensalada } \\
\text { mixta }\end{array}$ & 346 & 9 & 53 & 13 & 9 & 2 & 8 & 5 & 1 \\
\hline Total & 1.214 & 7 & 50 & 7 & 9 & 4.5 & 8 & 8 & 6.5 \\
\hline
\end{tabular}

\section{DISCUSIÓN}

Shigella es uno de los más importantes patógenos de origen alimentario causante de enfermedad diarreica tanto en países desarrollados como subdesarrollados (Hernández Cortez et al., 2011; Muñoz et al., 2013; WHO, 2005). Los registros epidemiológicos han mostrado que aproximadamente 140 millones de personas padecen shigelosis con una estimación de 600.000 defunciones por año en todo el mundo y el $60 \%$ de esas muertes acontecen en niños menores de 5 años (Ângela et al., 2013; Ergonul et al., 2004; Goud et al., 2018). Aunque en países del primer mundo la shigelosis se observa esporádicamente y habitualmente resulta de la transmisión fecal-oral de persona a persona a través de las manos, asociada a mala higiene personal, se describen sin embargo brotes ocasionales asociados a la ingestión de agua o alimentos contaminados o en instituciones cerradas, como albergues de ancianos, instituciones psiquiátricas o guarderías (Chang y Fang, 2007; Della Gaspera et al., 2015).

Las ensaladas preparadas, listas para consumir, habitualmente se preparan a partir de hortalizas que se hallen en un primer estadio de alteración microbiana, por supuesto descartando la zona afectada. Asimismo, son troceadas, aumentando de este modo la superficie específica de contacto con los nutrientes y agua con la flora microbiana presente. Este alimento generalmente se expende en envases de material plástico cubiertos con un film plástico termosellable y; por razones evidentes las hortalizas utilizadas como materia prima normalmente no reciben un tratamiento previo con una solución muy diluida de algún germicida como hipoclorito de sodio por algunos minutos y posterior lavado con agua potable. Esto no se efectúa debido a que sería dificultoso lograr a posteriori una reducción de la actividad acuosa, más aún en dichas condiciones de envasado es decir envase más film plástico termosellable, se obtendría una cámara húmeda y de esta forma se crearían las condiciones óptimas de multiplicación microbiana, aún bajo refrigeración debido a que dicha flora de acompañamiento mayoritariamente se caracteriza por ser psicrófila estricta o facultativa. 
En el presente trabajo ha sido posible aislar dos especies de Shigella, Shigella flexneri y Shigella boydii, siendo flexneri la obtenida con mayor frecuencia. Coincidiendo con los resultados obtenidos por Saima et al., (2018) quien analizando 50 ensaladas, listas para consumir durante 2017 en Quetta, Pakistán, en 16 muestras (32\%) detectó Shigella siendo flexneri la que prevaleció. Además comparó sus resultados con los obtenidos por otros investigadores quienes coincidieron con la misma especie en India, Egipto, Irán, Bangladesh, Pakistán, China, Indonesia y Vietnam.

Según otros investigadores Shigella spp. en muchas oportunidades puede hallarse encubierta dentro de las colonias de otros géneros bacterianos que manifiestan similares característica coloniales a esta enterobacteria patógena (Goud et al., 2018). Aunque en nuestro estudio no hemos hallado shigelas al emplear el aislamiento directo probablemente debido a su presencia en escaso número; al utilizar el enriquecimiento previo y aislamiento en agar MacConkey, el reaislamiento en idéntico agar selectivo y diferencial nos ha permitido su hallazgo y en muchas ocasiones estaban mezcladas con otras bacterias que incluso no presentaban las características fenotípicas de Shigella spp. En lo referente a las colonias falso positivas de los géneros bacterianos mencionados en resultados, cabe mencionar que Pantoea stewartii, dada la gran similitud en los resultados de todas las pruebas bioquímicas identificatorias de las especies de shigelas, recién se ha podido descartar mediante su identificación serológica. Además, Pantoea stewartii, así como Erwinia y Pectobacterium, fueron aislados con mayor frecuencia debido a que su hábitat normal son los vegetales como pudo apreciarse en la tabla 4 y se caracterizan por ser agentes fitopatógenos o de deterioro de estos alimentos. También en dicha tabla se observa que prevalecieron Pseudomonas, Alcaligenes, Aeromonas y otros bacilos Gram positivos habitualmente encontrados en suelo y aguas, mientras que Staphylococcus, aislado con alta frecuencia en este tipo de producto exclusivamente provendría de la manipulación a que están sujetos las hortalizas desde la cosecha hasta llegar al producto envasado, listo para consumir.

En lo que respecta al perfil de sensibilidad a los antimicrobianos, de los 13 aislamientos obtenidos de Shigella, $6(46,15 \%)$ manifestaron resistencia a ampicilina en el presente trabajo. Reda et al., (2011) obtuvo en cambio un $100 \%$ de resistentes, mientras que Goud et al., (2018) registró una resistencia de $82,3 \%$ respecto al antibiótico ampicilina. Mientras que en el caso de cefotaxima solamente $1(7,70 \%)$ de nuestros aislamientos de Sh. flexneri serotipo 2 manifestó resistencia a este antibiótico. En cambio los aislamientos de Della Gaspera et al., (2015) mostraron todos sensibilidad a cefotaxima. Con respecto a la ciprofloxacina hemos observado que $5(38,46 \%)$ manifestaron resistencia, Bhattacharya et al., (2012) alcanzó un $82 \%$ mientras que los aislamientos de Shigella de Mandomando et al., (2009), Della Gaspera et al., (2015) y Mardaneh et al., (2013) no mostraron resistencia a este antibiótico. En los que respecta al trimetoprim-sulfametoxazol $4(30,77 \%)$ manifestaron resistencia. Mardaneh et al., (2013) obtuvo un 92.2\%, Mandomando et al., (2009) $84 \%$ de resistencia y Jomezadeh et al., (2014) un $80.5 \%$ de resistencia, al comparar sus resultados con los de la presente investigación.

Por el contrario, Garedew et al., (2016) observó un 100\% de sensibilidad a este antibiótico por parte de sus aislamientos de Shigella. Para el cloranfenicol en el presente estudio Shigella spp. exhibió $30,77 \%$ de resistencia. Un valor muy similar fue obtenido por Jomezadeh et al., (2014) quien reportó 33,3\% de resistencia al cloranfenicol. Mayor resistencia a este antibiótico por parte de los aislamientos de Shigella fue observada por Brooks et al., (2006), con un 77\% de resistencia, y Asrat (2008) con un 74,7\% de resistencia. Mientras que los trabajos de Reda et al., (2011) y Goud et al., (2018) analizando los perfiles de sensibilidad antimicrobiana de Shigella, mencionan solo un $29,4 \%$ y $17,7 \%$ respectivamente. Mientras que en furazolidona solamente $1(7,70 \%)$ de los aislamientos de Sh. flexneri serotipo 1 manifestó resistencia a este antibiótico. Contrariamente los aislamientos de Della Gaspera et al., (2015) mostraron sensibilidad a furazolidona. Cabe destacar que en nuestro presente estudio $4(30,77 \%)$ aislamientos de Shigella flexneri serotipo 2 manifestaron una multirresistencia a tres de los antibióticos evaluados básicamente a ampicilina, trimetoprimsulfametoxazol y cloranfenicol. Shigella spp. ha mostrado tendencias constantes hacia la resistencia a múltiples fármacos, probablemente por la adquisición de ADN extracromosómico a través de plásmidos, transposones R', mutación celular, entre otros. En algunos casos, esto ha limitado la acción de los antibióticos por acción de enzimas microbianas (Russel y Path, 2001; Lery, 2002).

El uso excesivo de antibióticos selecciona organismos resistentes a estos fármacos $\mathrm{y}$, por lo tanto, la terapia antimicrobiana para la shigelosis debería reservarse solo para los pacientes más gravemente enfermos. Los antibióticos no sustituyen las adecuadas condiciones higiénico-sanitarias que limitan la diseminación secundaria de la shigelosis. La medida más efectiva y simple de prevenir su transmisión es el lavado de manos con jabón y agua clorada. La manipulación y preparación de alimentos son procesos importantes que también merecen suma atención. Las personas con sintomatología de alteración intestinal deberían excluirse de la manipulación de los alimentos. Debido a que todavía no han sido diseñados medios de cultivo tanto de enriquecimiento como de aislamiento, capaces de permitir la óptima recuperación de shigelas y paralelamente inhibir a la flora bacteriana de acompañamiento, poder aislar shigellas en una muestra alimenticia y ambiental es muy dificultoso. Este concepto fue corroborado por Della Gaspera et al., (2015) al investigar un brote por 
Shigellla sonnei ocurrido en julio de 2012 en la ciudad de Luján, Buenos Aires, Argentina, donde se aisló y caracterizó Shigella sonnei de una muestra de crema de almendras empleada en la preparación de una rosca vienesa responsable del brote. La recuperación de esta enterobacteria se logró mediante un plaqueo directo en agar tripticasa de soja-extracto de levadura, y aunque esta metodología sería más laboriosa, con ella se llegó a lograr el objetivo buscado no así utilizando una metodología estandarizada.

Cabe destacar que la relativa facilidad de detectar shigelas en muestras fecales de pacientes con disentería bacilar se debería a que en este tipo de muestras el microorganismo prevaleciente es Shigella spp. Esta situación no ocurre en las muestras alimenticias y ambientales. Esto nos permite explicar porque en nuestro estudio ha resultado imposible su hallazgo bajo la metodología de aislamiento directo. En este material prevaleció la flora competitiva mencionada en los resultados, consistente en microorganismos presentes tanto en el suelo como en los tejidos vegetales. Asimismo, debe rescatarse la importancia de realizar siempre la tipificación serológica, principalmente cuando se busca detectar shigelas en vegetales frescos debido a que están constituidos mayormente por Pantoea stewartii, que en nuestro estudio llegó a ocupar alrededor del $50 \%$ de los falsos positivos por pruebas bioquímicas. Debe tenerse en consideración que el porcentaje de muestras positivas de shigelas luego del enriquecimiento en agua de peptona tamponada podría considerarse un valor subestimado debido a su considerable labilidad por lo que la mayoría de investigadores recomiendan utilizar las técnicas de biología molecular para llegar a una mayor aproximación al número real de muestras que vehiculizan esta enterobacteria patógena como menciona Mokhtari et al., (2012) quien utilizó la técnica de Reacción en Cadena de Polimerasa luego de una fase de enriquecimiento en caldo Shigella con la adición de novobiocina $(0,5 \mu \mathrm{g} \mathrm{mL}-1)$, logrando con ello eliminar las células muertas por efecto diluyente y simultáneamente aumentó el porcentaje de positividad tanto en muestras de alimentos como de especímenes clínicos en comparación con las técnicas habituales de cultivo estándares.

\section{CONCLUSIONES}

De acuerdo a los resultados se pueden extraer las siguientes 4 conclusiones principales:

1.- La presencia de shigelas en estos alimentos podría estar subestimada.

2.- De todos modos, su hallazgo en algunas muestras implicaría un alto riesgo de adquirir la enfermedad debido a su baja dosis infectiva para ocasionarla.

3.- Resulta conveniente vigilar minuciosamente al manipulador en todas las etapas del proceso pero principalmente en la preparación de la ensalada y envasado debido a la labilidad de esta enterobacteria a las condiciones ambientales.

4.- Debido a que las ensaladas no requieren un tratamiento térmico adicional, es importante el lavado de tales verduras y hortalizas así como sumergirlas por un tiempo adecuado en algún químico antibacteriano con la finalidad de eliminar patógenos y reducir significativamente la carga microbiana residual.

\section{AGRADECIMIENTOS}

A la Universidad Nacional de Luján y al Departamento de Ciencias Básicas por el apoyo recibido para la ejecución del proyecto.

\section{REFERENCIAS}

Ângela Bernardes Sousa, M., E. Nogueira Mendes y otros cuatro autores, Shigella in Brazilian Children with Acute Diarrhea: Prevalence, Antimicrobial Resistance and Virulence Genes, doi: 10.1590/S0074-02762013000100005, Mem. Inst. Oswaldo Cruz, 108, 30-35 (2013)

Asrat, D., Shigella and Salmonella Serogroups and their Antibiotic Susceptibility Patterns in Ethiopia, East. Mediter. Health J., 14, 160-167 (2008)

Bad Bug Book, Foodborne Pathogenic Microorganisms and Natural Toxins, 2nd Ed., 22-25. Food and Drug Administration (2012)

Barrantes, C.E.G., A. Guillén y otros tres autores, Serotipos y Resistencia Antibiótica en Shigella spp. Aisladas de Infecciones Intestinales, ECI Perú, 10, 34-41 (2013)

Bhattacharya, D., A.P. Sugunan y otros cuatro autores, Antimicrobial Resistance in Shigella-Rapid Increase and Widening of Spectrum in Andaman Islands, India, Indian J. Med. Res., 135, 365 (2012)

Biniam, G. y A. Mogessie, Microbial Load, Prevalence and Antibiograms of Salmonella and Shigella in Lettuce and Green Peppers, Ethiop. J. Health Sci., 20, 41-48 (2010) 
Brandl, M.T., Fitness of human enteric pathogens on plants and implications for food safety, Ann. Rev. Phytopathol., 44, 367-392 (2006)

Brooks, J.T., J.B. Ochieng y otros cuatro autores, Surveillance for Bacterial Diarrhea and Antimicrobial Resistance in Rural Western Kenya, 1997-2003, Clin. Infect. Dis., 43, 393-401 (2006)

Chang, J. y T.J. Fang, Survival of Escherichia coli 0157:H7 and Salmonella enterica serovars Typhimurium in iceberg lettuce and the antimicrobial effect of rice vinegar against E. coli 0157:H7, Food Microbiol., 24, 745-751 (2007)

Della Gaspera, A., M.I. Caffer y otros cinco autores, Brote de Shigelosis en la Ciudad de Luján, Argentina, Informe Breve, ISSN 0325-7541, Rev. Argent. Microbiol., 47, 112-117 (2015)

Deza, M.A., M. Araujo y M.J. Garnido, Inactivation of Escherichia coli 0157:H7, Salmonella enteritidis and Listeria monocytogenes on the surface of tomatoes by neutral electrolyzed water. Lett. Appl. Microbiol., 37, 482-487 (2003)

Ergonul, Ö., A. İmre, A. Çelikbaş y B. Dokuzoğuz, Drug Resistance of Shigella Species: Changes over 20 Years in Turkey, Int. J. Antimicrobial. Ag., 23, 527-528 (2004)

Food Microbiology, Fundamentals and Frontiers, 4th Ed., 377-399. Michael P. Doyle and Robert L. Buchanan Washington (2013)

Garedew, L., Z. Hagos, B. Zegeye y Z. Addis, The Detection and Antimicrobial Susceptibility Profile of Shigella Isolates from Meat and Swab Samples at Butchers' Shops in Gondar Town, Northwest Ethiopia, J. Infect. Public Health, 9, 348355 (2016)

Goud, S., S. Raghavendra, M. Shylaja y J. Babu, The Detection and Antimicrobial Susceptibility Profile of Shigella Isolates in and Around Hyderabad, Telangana, J. Pharm. Innov., 7, 84-88 (2018)

Haley, C.C., K.L. Ong y otros quince autores, Risk Factors for Sporadic Shigellosis, Food Net 2005, Foodborne Pathog. Dis., 7,741 (2010)

Hernández Cortez C., M. G. Aguilera Arreola y G. Castro Escarpulli, Situación de las Enfermedades Gastrointestinales en México, Enferm. Infecc. Microbiol. Clin., 31, 137-51 (2011)

Jomezadeh, N., S. Babamoradi, E. Kalantar y H. Javaherizadeh, Isolation and Antibiotic Susceptibility of Shigella Species from Stool Samples among Hospitalized Children in Abadan, Iran, Gastroenterol. Hepatol. Bed Bench., 7, 218 (2014)

Lery, S. B., The Antibiotic Paradox: How Misuse of Antibiotics Destroy their Curative Powers, 2nd Ed., 39-41.Oxford University Press (2002)

Mandomando, I., J. Dinis, y otros cinco autores, Antimicrobial Susceptibility and Mechanisms of Resistance in Shigella and Salmonella Isolates from Children less than Five Years of Age with Diarrhea in Rural Mozambique, Antimicrob. Agents Chemother, 53(6), 2450-2454 (2009)

Manual of Methods of Analysis of Foods: Water, 1st Ed., 214-221. Ministry of Health and Family Welfare, Government of India, New Delhi (2016)

Mardaneh, J., S.A. Poor y P. Afrugh, Prevalence of Shigella Species and Antimicrobial Resistance Patterns of Isolated Strains from Infected Pediatrics in Tehran, Int. J. Enteric. Pathog., 1, 28-31 (2013)

Mokhtari, W. y otros cinco autores. Detection and Characterization of Shigella Species Isolated from Food and Human Stool Samples in Nabeul, Tunesia, by Molecular Methods and Culture Techniques, ISSN: 1364-5072, J. Appl. Microbiol., 113, 209-222 (2012)

Muñoz, S.J., M.L. Vilca, D.D. Ramos y J.L. Lucas, Frecuencia de Enterobacterias en Verduras Frescas de Consumo Crudo Expendidas en Cuatro Mercados de Lima, Perú, Rev. Inv. Vet. Peru, 24, 300-306 (2013)

Nutt, J.D., X. Li y otros tres autores, Growth kinetics response of a Salmonella Typhimurium poultry marker strain to fresh produce extracts, Bioresource Technol, 89, 313-316 (2003)

Petri, W.A., M. Miller y otros cuatro autores, Enteric Infections, Diarrhea and their Impact on Function and Development, J. Clin. Invest., 118(4), 1277-1290 (2008)

Reda, A.A., B. Seyoum y otros tres autores, Antibiotic Susceptibility Patterns of Salmonella and Shigella Isolates in Harar, Eastern Ethiopia, J. Infect. Dis. Immun., 3, 134-139 (2011)

Russel, A. y F.R.C. Path, Mechanism of Bacterial Insusceptibility to Biocide, Am. J. Infect. Control, 29, 259-261 (2001)

Saima, A.S. y otros diez autores, Isolation and Identification of Shigella Species from Food and Water Samples of Quetta, Pakistan, doi: 10.19045/bspab.2018.70027, Pure Appl. Biol., 7, 227-235 (2018)

World Health Organization, Guidelines for the Control of Shigellosis including Epidemics due to Shigella dysenteriae type 1 (2005) 